Check for updates

Cite this: Mater. Adv., 2021, 2, 5967

Received 28th April 2021,

Accepted 3rd August 2021

DOI: 10.1039/d1ma00383f

rsc.li/materials-advances

\section{An anticounterfeiting technology combining an InP nanoparticle ink and a versatile optical device for authentication $\dagger$}

\begin{abstract}
Didem Taşcıoğlu, (D) ab Seçil Sevim Ünlütürkł and Serdar Özçelik (D) *c
Counterfeiting is a growing issue and causes economic losses. Fluorescent inks containing $\ln (\mathrm{Zn}) \mathrm{P} / \mathrm{ZnS} /$ DDT colloidal nanoparticles are formulated and combined with a convenient optical device for authentication. The particle size and fluorescent colors of the colloidal nanoparticles were tuned by adjusting the reaction temperature. The particle stability and brightness were improved by the addition of dodecanethiol, coating the particle surface with an organic shell. Security patterns were printed on various substrates by applying the screen-printing technique. The patterns were invisible under daylight but observable under UV-light illumination, displaying five different emission colors. By adjusting the concentration of the nanoparticles in the ink, the security patterns were made almost not observable under UV-light illumination but clearly identified by a commercial fiber optics-based spectrometer and a handheld optical device, called a Quantag sensor that was developed in-house. Furthermore, the spectral signatures of barely noticeable patterns are unambiguously validated by the Quantag sensor. Accordingly, low cost and easily applicable anticounterfeiting technology powered by custom-formulated fluorescent inks and a handheld optical instrument are developed to authenticate valuable documents and products.
\end{abstract}

\section{Introduction}

Counterfeiting and adulteration of valuable documents cause economical losses and initiate societal concerns. Anticounterfeiting efforts require advanced materials and technologies to prevent counterfeiting. Fluorescent inks are commonly used as secondlevel security features; being invisible in the daylight and detectable under UV light. In the last decade, to prevent counterfeiting, security labels have been created using different printing techniques with various fluorescent inks formulated by using rare earth luminescent materials, ${ }^{1-6}$ perovskite nanocrystals, ${ }^{7,8}$ carbon dots, ${ }^{9-11}$ organic dyes, ${ }^{12,13}$ and quantum dots. ${ }^{14-16}$ Among various printing methods, screen printing is preferable because it is easily applicable to various substrates. ${ }^{17}$ Screen printing is a unique technique in terms of

\footnotetext{
${ }^{a}$ Department of Material Science and Engineering, Izmir Institute of Technology, Urla, 35430, İmir, Turkey

${ }^{b}$ Quantag Nanotechnologies, R\&D Lab, Budotek Teknopark, Dudullu OSB Ümraniye, 34776, İstanbul, Turkey

${ }^{c}$ Department of Chemistry, Izmir Institute of Technology, Urla, 35430, Izmir, Turkey.E-mail: serdarozcelik@iyte.edu.tr; Tel: +90 2327507557

$\dagger$ Electronic supplementary information (ESI) available: DDT effect on photophysical properties and relevant characterization details and supporting photographs; the photo of the screen printing device; the PL spectra of varnish and screen printed paper samples (PDF). See DOI: 10.1039/d1ma00383f

\# The current address of the author, Seçil SEVIM ÜNLÜTÜRK, is Micro-ElectroMechanical Systems Research and Application Center (METU-MEMS), Middle East Technical University, Çankaya, 06530, Ankara, Turkey.
}

quality; it is a process that uses ink or pastes pushed by a template attached or embedded in a web stretched onto a printing frame. Since an intermediate transfer tool is not required, the consistency of the ink is not limited. Long-lasting and durable prints can be produced, providing unrivaled homogeneity and color brilliance. Screen printing can be applied to a variety of substrates from papers to metals to plastics, and even glass and ceramics. These capabilities enable the production of a wide variety of products including smart identity cards, credit cards, technical and industrial parts, automobile components, flat glass and glass containers, etc. ${ }^{18}$

In the past several years, publications applying screen-printing techniques using lanthanide-based luminescent materials have been widely reported for anticounterfeiting. ${ }^{6,19-22}$ Organic dyes as fluorescent materials are used in this field. ${ }^{12,23}$ Colloidal quantum dots (CQDs) are considered alternatives to these materials because of their unique optical properties. ${ }^{24,25}$ Unlike the lightfastness and cost-effectiveness of lanthanide-based materials and broad emission peaks of organic dyes, ${ }^{26}$ cQDs possess narrow, stable, and tunable photoluminescence emission features. ${ }^{27}$ In addition, cQDs may be excited by a single wavelength light source because of their broad absorption spectra. With all these distinctive features, CQDs may be regarded as an excellent anticounterfeiting material for contemporary security ink and printing technology.

To prevent counterfeiting, luminescent/fluorescent materials are turned into colorless fluorescent inks that exhibit confidential information when exposed to UV light. ${ }^{28-30}$ 
However, as these materials often exhibit monochromatic emissions that are easy to imitate, these security inks offer a low level of protection against counterfeiting. In recent years, luminescent inks made of rare-earth materials have attracted great attention due to their fast response time, high brightness, and efficiency. ${ }^{31-34}$ However, rare-earth materials-based security inks severely limit scaled-up production due to high cost. Furthermore, it is desired to verify the authenticity of a document illuminated under UV light by visual inspection without using a device. ${ }^{29,32}$ However, this simplicity would make security patterns predictable and can be easily reproduced. To prevent counterfeiting, utilizing an affordable, widely-used, handy instrument such as a mobile phone or an optical device working with a specially formulated ink may enhance anticounterfeiting procedures.

In this study, we formulated a colloidal nanoparticle (colloidal quantum dot)-based security ink to authenticate valuable documents. Here, we chose indium-based alloyed nanoparticles because the cost of indium-based precursors is much lower than that of the rare-earth element-based materials. On top of that, they can be easily produced at hundreds of grams in one pot, ${ }^{35,36}$ thereby further lowering the ink cost. Herein, we synthesized $\operatorname{In}(\mathrm{Zn}) \mathrm{P} / \mathrm{ZnS} / \mathrm{DDT}$ nanoparticles to formulate security inks emitting brightly in various colors. Fluorescence properties of the nanoparticles were adjusted by the reaction temperature, tuning the particle size generating various fluorescent colors. The $\operatorname{In}(\mathrm{Zn}) \mathrm{P} / \mathrm{ZnS} / \mathrm{DDT}$ colloidal nanoparticles were mixed with a commercial printing varnish to formulate security inks. The inks were used to print security patterns on various substrates including paper, polymer, and glass by applying the screen-printing technique. The security patterns printed were evaluated by using a commercial fiber opticsbased spectrometer, and a low-cost, convenient handheld optical device, called a Quantag sensor developed in-house by Quantag Nanotechnologies. The security patterns that were barely detectable under UV light by the naked eye were clearly detectable by the Quantag sensor. The spectral features, wavelengths, and brightness, were validated by a fiber optics-based spectrometer, verifying the readings of the Quantag sensor. It is demonstrated that the security patterns can be printed by using the specially formulated ink and detected at a low cost, using a simple and handy optical device to authenticate the originality of documents or products.

\section{Experimental}

\subsection{Materials and methods}

Indium(III) chloride $\left(\mathrm{InCl}_{3}, 98 \%\right)$, oleylamine (OA, 70\%), trioctylphosphine (TOP, 97\%), zinc stearate (technical grade), 1octadecene (ODE, 90\%), 1-dodecanethiol (DDT, $\geq 98 \%$ ), sulfur (Merck, 99\%) and toluene (ACS reagent, $\geq 99.7 \%$ ) were purchased from Sigma-Aldrich. Zinc(II) chloride $\left(\mathrm{ZnCl}_{2}, 97 \%\right)$ and tris(diethylamino)phosphine ((DEA) $\left.{ }_{3} \mathrm{P}, 97 \%\right)$ were purchased from Alfa Aesar. Printcolor series 592 varnish was used to formulate inks.
Photoluminescence (PL) and quantum yield (QY)\% measurements were performed using a Horiba-Fluorolog with an integrated sphere or USB2000 fiber optics-based spectrometer (Ocean Optics Inc., Dunedin, FL, USA). Absorbance was measured using a Shimadzu UV-3600 UV-vis-NIR spectrophotometer. Particle size measurements were obtained using a DLS (Malvern ZS-Zetasizer). SEM-EDS analysis employed an FEI QUANTA 250 FEG SEM equipped with an Oxford Instruments energy dispersive X-ray analyzer. XRD patterns were obtained using a Bruker D2 phaser-X-ray diffractometer. Fourier transform infrared spectroscopy (FTIR; Thermo Scientific iS10 FT-IR) was used to confirm DDT coating. The thickness of the screen-printed patterns was measured using a KlaTencor MicroXM-100 optical profilometer. An Andor Revolution confocal microscope was used to determine ink homogeneity in the printed patterns. The Quantag sensor is a fiber optics-based device developed in-house (patent protected). It is a handheld and low-cost optical instrument utilizing fiber optical probes to detect and measure fluorescence intensity (brightness) and colors (wavelength) of inks embedded into patterns printed on substrates.

\subsection{Synthesis of $\operatorname{In}(\mathrm{Zn}) \mathrm{P}$ core and $\mathrm{In}(\mathrm{Zn}) \mathrm{P} / \mathrm{ZnS} / \mathrm{DDT}$ core/shell nanoparticles}

In(Zn)P/ZnS/DDT colloidal nanoparticles were synthesized by applying a modified hot injection method. ${ }^{37}$ Briefly, $0.9 \mathrm{mmol}$ of $\mathrm{InCl}_{3}$ and $4.4 \mathrm{mmol}$ of $\mathrm{ZnCl}_{2}$ were mixed in $10.0 \mathrm{~mL}$ of oleylamine at $120{ }^{\circ} \mathrm{C}$ and stirred for $20 \mathrm{~min}$. After the indium and zinc precursors were completely dissolved under a nitrogen atmosphere, the reaction temperature was increased to a specific predetermined value (varied from 150 to $200{ }^{\circ} \mathrm{C}$ ). $3.3 \mathrm{mmol}$ tris(diethylamino)phosphine $\left((\mathrm{DEA})_{3} \mathrm{P}\right)$ was rapidly injected into the precursor solution to synthesize the core of In(Zn)P nanoparticles. To coat the nanoparticle surface with a ZnS shell, TOP-S and Zn(stearate) $)_{2}$ were prepared individually and added dropwise into the $\mathrm{In}(\mathrm{Zn}) \mathrm{P}$ core nanoparticle dispersion. Firstly, $2 \mathrm{~mL}$ of $2.2 \mathrm{M}$ TOP-S and $8 \mathrm{~mL}$ of $0.4 \mathrm{M}$ $\mathrm{Zn}$ (stearate $)_{2}$ solutions were simultaneously injected into the reaction medium and the reaction temperature was increased to $300{ }^{\circ} \mathrm{C}$. After one hour, $1.4 \mathrm{~mL}$ of $2.2 \mathrm{M}$ TOP-S and $8 \mathrm{~mL}$ of $0.4 \mathrm{M} \mathrm{Zn}$ (stearate $)_{2}$ solutions were added as the second injection. The formation of additional layers was established at 30 min and $15 \mathrm{~min}$, respectively, following the second injection. After the formation of a multilayered $\mathrm{ZnS}$ shell coating, the reaction was cooled down to $120^{\circ} \mathrm{C}$. At this temperature, DDT was injected into the dispersion to grow an organic passivation layer over the nanoparticle surface. The dispersion was stirred for 20 minutes more and then the reaction was terminated by cooling the dispersion to room temperature (Fig. S1, ESI $\dagger$ ).

To purify the crude $\operatorname{In}(\mathrm{Zn}) \mathrm{P} / \mathrm{ZnS} / \mathrm{DDT}$ nanoparticles, the dispersion was precipitated by the addition of ethanol and then centrifugated at $6000 \mathrm{rpm}$ for 15 minutes. This purification step was repeated one more time to remove remaining unreacted precursors and excessive amounts of organics. Purified $\mathrm{In}(\mathrm{Zn}) \mathrm{P} / \mathrm{ZnS} / \mathrm{DDT}$ nanoparticles were dried under a vacuum and stored as powders. 


\subsection{Printing process}

$\mathrm{In}(\mathrm{Zn}) \mathrm{P} / \mathrm{ZnS} / \mathrm{DDT}$ nanoparticles were dispersed in a commercial varnish/toluene mixture with a ratio of $0.1-0.2 \% \mathrm{v} / \mathrm{v}(1000-$ $2000 \mathrm{ppm})$. This ink was used to print security patterns on various substrates by using a screen-printer.

\section{Results and discussions}

\subsection{In(Zn)P/ZnS/DDT nanoparticles}

Recently, III-V semiconductors have gained attention because they have typically a higher covalent character than ionic materials (II-VI and IV-VI materials), resulting in improved optical stability and lower toxicity. ${ }^{38}$ The Bohr radii of III-V systems are larger compared to II-VI materials, which create stronger quantum confinement. ${ }^{39}$ InP among all III-V semiconductors is of great interest due to its stability and low toxicity compared to heavy metals cadmium and mercury. ${ }^{40}$ The bulk bandgap of InP is $1.35 \mathrm{eV}$ (918 nm) having a large Bohr radius that generates a wider optical range from visible to near-infrared (NIR). ${ }^{41}$ We preferred to synthesize In(Zn)P/ZnS/DDT colloidal nanoparticles for anticounterfeit applications because of low toxicity and high brightness.

As shown in Fig. 1, increasing the reaction temperature resulted in redshifts in the absorption spectra. The particle size of the nanoparticle core was measured by the DLS (dynamic light scattering) technique (Fig. 1b), confirming that the increase in nanoparticle size from 5.6 to $13.5 \mathrm{~nm}$ was correlated to the observed red-shifted absorption spectra. Despite a well-defined absorption band of $\operatorname{In}(\mathrm{Zn}) \mathrm{P}$ core nanoparticles, weak photoluminescence was observed. Nonradiative relaxations due to the surface defects cause weaker emissions for InP nanoparticles unless a proper inorganic shell is coated on the surface of the core nanoparticle. ${ }^{42}$ XRD patterns of the core nanoparticles revealed the formation of low-quality nanocrystalline structures (Fig. S2a, ESI $\dagger$ ). XRD measurements indicated the formation of the ZnO layer (JCPDS: 36-1451) on the particle surface due to the oxidation of Zn ions (Fig. S2a, ESI $\dagger$ ). As demonstrated in the literature, ${ }^{43,44}$ the InP core generally generates low fluorescence emission (quantum yield less than $1 \%$ ) and is prone to photodegradation and surface oxidation. Coating the core with a larger bandgap semiconductor material such as $\mathrm{ZnS}$ is a common method to improve fluorescence efficiency by passivating the core surface and diminishing dangling bonds. ${ }^{45}$ Herein, $\mathrm{ZnS}$ was chosen as the shell layer material because it has high chemical stability and a wide bandgap $(3.6 \mathrm{eV})$, and low-cost precursors are commercially available. ${ }^{46,47}$ When the core nanoparticle was coated with $\mathrm{ZnS}$ shell, In(Zn)P/ZnS nanoparticles emitted in the range of 535$638 \mathrm{~nm}$ with higher quantum yields (Fig. 2b and Table 1). XRD patterns show better diffractograms suggesting improved crystal structures and well-defined (111), (220), and (311) facets established after ZnS/DDT shell growth on the particle surface (Fig. S2b and c, ESI $\dagger$ ).

The fluorescent colors of the nanoparticles were tuned by adjusting the reaction temperature, which increased from 150 to $200{ }^{\circ} \mathrm{C}$. The bright visible emission under UV illumination is an indication of the highly efficient fluorescence emission shown in the inset of Fig. 2a. For all reaction temperatures, the FWHM of nanoparticles were comparable (Fig. 2b). (DEA) ${ }_{3} \mathrm{P}$ was used as the phosphorus source because its higher steric hindrance reduces chemical reactivity and consequently leads to stable and high-quality nanocrystals. ${ }^{37,45}$ Other phosphorus sources tris(trimethylsilyl)-phosphine ((TMS) $\left.)_{3} \mathrm{P}\right)$, and tris(dimethylamino) phosphine $\left((\mathrm{DMA})_{3} \mathrm{P}\right)$ were not chosen because (TMS $)_{3} \mathrm{P}$ is highly flammable, toxic, and expensive ${ }^{37}$ and $(\mathrm{DMA})_{3} \mathrm{P}$ has high reactivity because it has lower steric hindrance. ${ }^{48}$

The point of incorporating $\mathrm{Zn}$ ions into the InP crystal was to reduce structural strain due to lattice mismatch between the InP core and $\mathrm{ZnS}$ shell layer. ${ }^{49,50}$ Incorporated $\mathrm{Zn}$ ions alleviate the lattice tension ${ }^{51}$ between the core and the shell layers. The successful growth of the $\mathrm{ZnS}$ ensures higher quantum
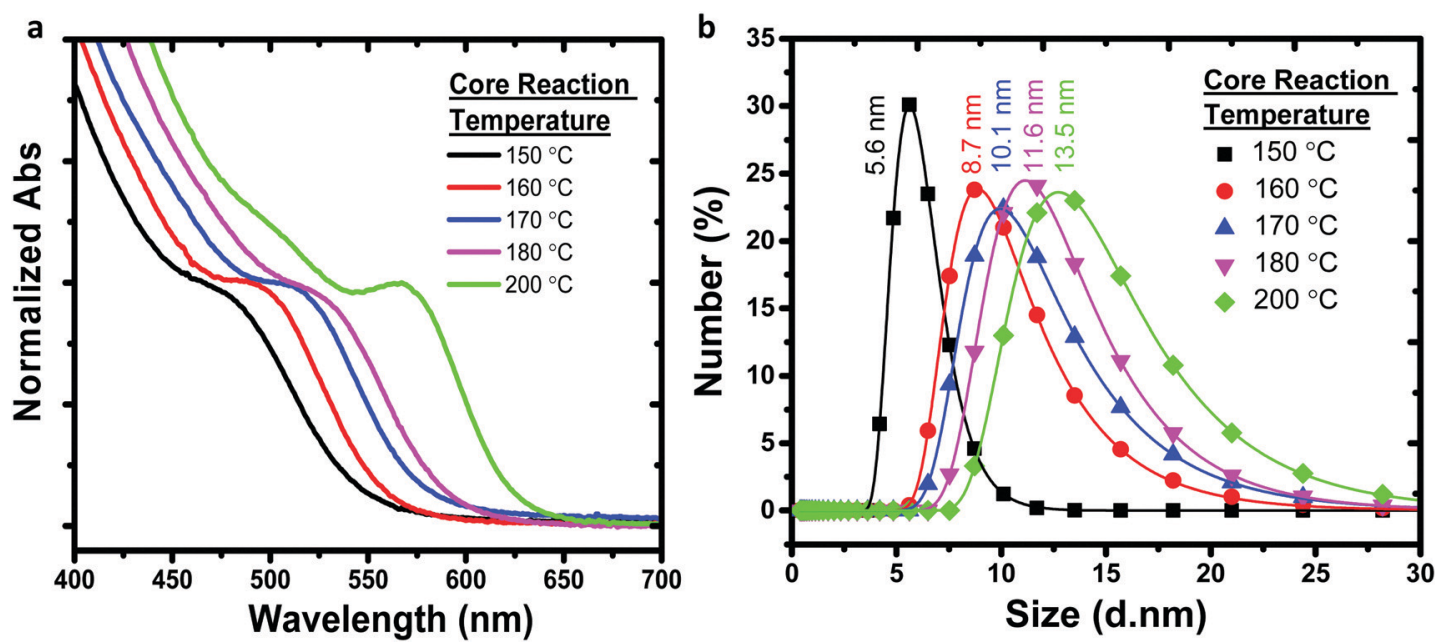

Fig. 1 (a) Absorption spectra and (b) particle size and distribution of $\ln (\mathrm{Zn}) \mathrm{P}$ core nanoparticles, tuned by the reaction temperature but keeping the reaction time fixed. 
a

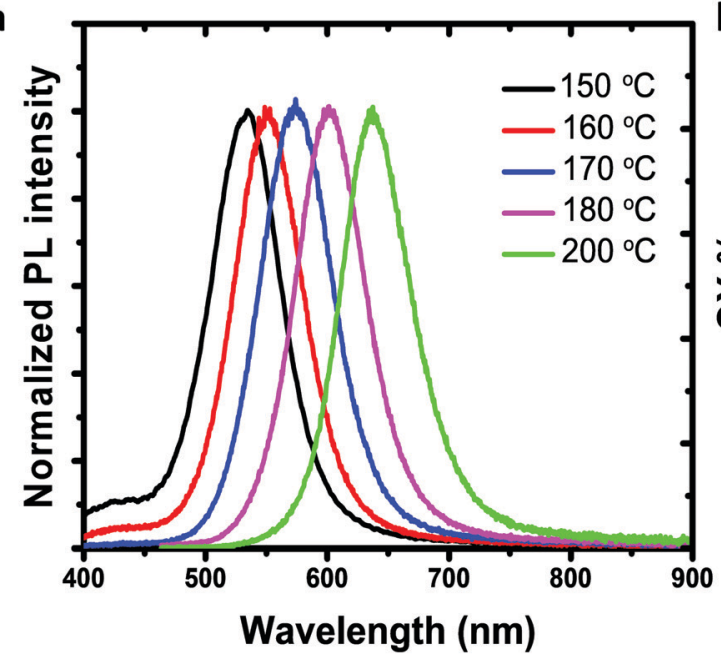

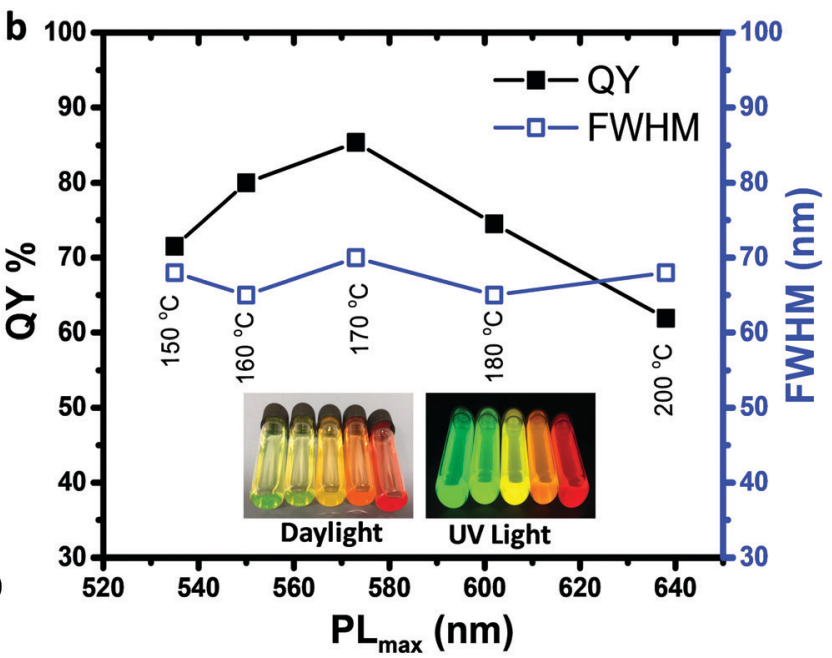

Fig. 2 (a) Fluorescence spectra of $\ln (\mathrm{Zn}) \mathrm{P} / \mathrm{ZnS} / \mathrm{DDT}$ core/shell nanoparticles tuned by the reaction temperature. Excitation wavelengths for the samples from $150{ }^{\circ} \mathrm{C}$ to $200{ }^{\circ} \mathrm{C}$ are $365 \mathrm{~nm}, 375 \mathrm{~nm}, 375 \mathrm{~nm}, 405 \mathrm{~nm}$, and $450 \mathrm{~nm}$, respectively. (b) Evolution of the fluorescence quantum yield (QY) percent and the FWHM of the spectra with respect to the emission wavelengths (increasing core reaction temperature resulted in a redshift in fluorescence maxima from left to right). Highly concentrated samples were deliberately prepared to exhibit fluorescence colors under daylight and UV-light illumination.

Table 1 Photophysical properties of $\ln (\mathrm{Zn}) \mathrm{P} / \mathrm{ZnS} / \mathrm{DDT}$ nanoparticles prepared at various reaction temperatures

\begin{tabular}{llllll}
\hline Reaction temperature & $\begin{array}{l}\mathrm{PL}_{\text {max }} \\
(\mathrm{nm})\end{array}$ & $\begin{array}{l}\mathrm{Abs}_{\max } \\
(\mathrm{nm})\end{array}$ & $\begin{array}{l}\text { Stokes shift } \\
(\mathrm{nm})\end{array}$ & $\begin{array}{l}\text { FWHM } \\
(\mathrm{nm})\end{array}$ & $\begin{array}{l}\text { QY } \\
(\%)\end{array}$ \\
\hline $150{ }^{\circ} \mathrm{C}$ & 535 & 470 & 65 & 68 & 72 \\
$160{ }^{\circ} \mathrm{C}$ & 550 & 490 & 60 & 65 & 80 \\
$170{ }^{\circ} \mathrm{C}$ & 573 & 505 & 68 & 70 & 85 \\
$180{ }^{\circ} \mathrm{C}$ & 602 & 518 & 84 & 65 & 75 \\
$200{ }^{\circ} \mathrm{C}$ & 638 & 565 & 63 & 68 & 62
\end{tabular}

yields for the alloyed nanoparticles. Atom\% values of the elements for In(Zn)P core nanoparticles were determined using SEM-EDS measurements and are provided in Table 2. Fig. 3 demonstrates that the fractions of $\mathrm{Zn}$ and In in the alloy were not varying with the reaction temperatures. The alloy composition of the core remained unchanged with the reaction temperature. This finding suggested that the red-shifted spectra (absorption and photoluminescence) were tuned by the particle size rather than the alloy composition. Since the ionic radius of $\mathrm{In}^{3+}(80 \mathrm{pm})$ is not significantly larger than the ionic radius of $\mathrm{Zn}^{2+}(74 \mathrm{pm}),^{52}$ it was demonstrated that by keeping the reaction time fixed the reaction temperature is an effective parameter to tune the particle size and to regulate the spectral

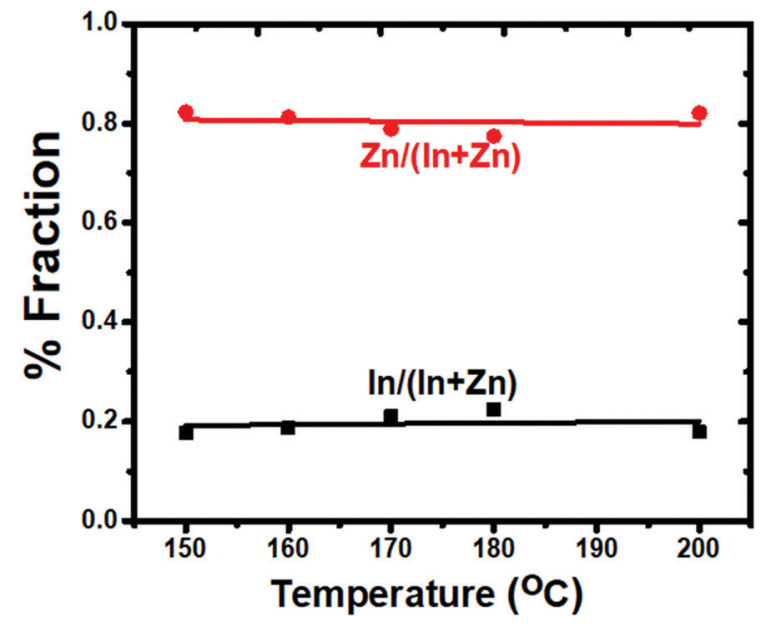

Fig. 3 Variation of $\mathrm{Zn}$ and $\mathrm{In}$ fractions of the nanoparticles as a function of the reaction temperature, determined by SEM-EDS measurements. The compositions of the core nanoparticles remained constant.

properties of $\operatorname{In}(\mathrm{Zn}) \mathrm{P}$ nanoparticles. In general, the reaction time is preferred to tune particle size keeping the reaction temperature constant. Higher reaction temperatures did not

Table 2 Alloy compositions and particle diameters of core $\ln (\mathrm{Zn}) \mathrm{P}$ nanoparticles synthesized at different reaction temperatures, analyzed by SEM-EDS and DLS measurements

\begin{tabular}{|c|c|c|c|c|c|c|c|c|}
\hline \multirow[b]{2}{*}{ Reaction temperature } & \multirow[b]{2}{*}{ Core type } & \multicolumn{6}{|c|}{ Atom \% } & \multirow[b]{2}{*}{ Size (nm) } \\
\hline & & $\mathrm{P}$ & $\mathrm{Zn}$ & In & $\operatorname{In} /(\operatorname{In}+\mathrm{Zn})$ & $\mathrm{Zn} /(\mathrm{In}+\mathrm{Zn})$ & $\mathrm{Zn} / \mathrm{In}$ & \\
\hline $150{ }^{\circ} \mathrm{C}$ & $\mathrm{In}_{0.18} \mathrm{Zn}_{0.82} \mathrm{P}$ & 15.8 & 69.3 & 14.9 & 0.18 & 0.82 & 4.7 & 5.6 \\
\hline $160^{\circ} \mathrm{C}$ & $\mathrm{In}_{0.19} \mathrm{Zn}_{0.81} \mathrm{P}$ & 16.9 & 67.6 & 15.6 & 0.19 & 0.81 & 4.3 & 8.7 \\
\hline $170{ }^{\circ} \mathrm{C}$ & $\mathrm{In}_{0.21} \mathrm{Zn}_{0.79} \mathrm{P}$ & 14.4 & 67.6 & 18.1 & 0.21 & 0.79 & 3.7 & 10.1 \\
\hline $180^{\circ} \mathrm{C}$ & $\mathrm{In}_{0.23} \mathrm{Zn}_{0.77} \mathrm{P}$ & 29.3 & 54.8 & 16.0 & 0.23 & 0.77 & 3.4 & 11.6 \\
\hline $200{ }^{\circ} \mathrm{C}$ & $\mathrm{In}_{0.18} \mathrm{Zn}_{0.82} \mathrm{P}$ & 21.9 & 64.1 & 14.0 & 0.18 & 0.82 & 4.6 & 13.5 \\
\hline
\end{tabular}




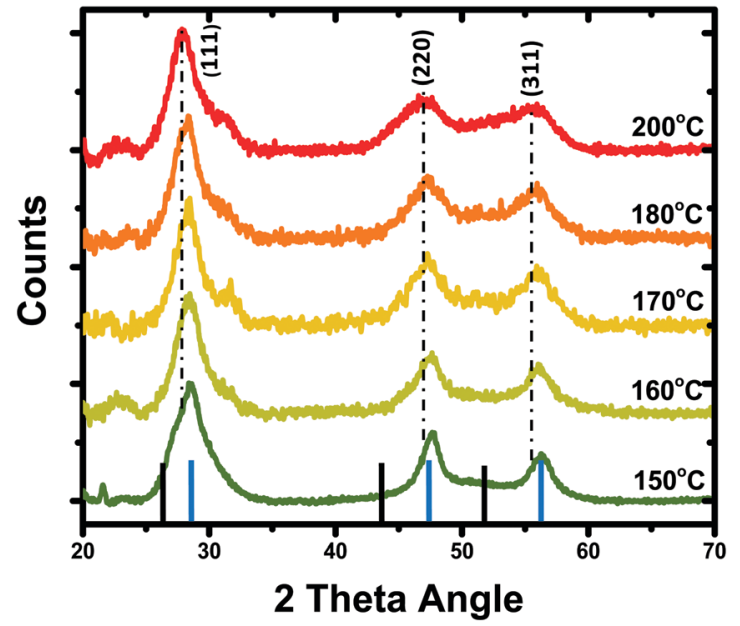

Fig. 4 XRD patterns of $\operatorname{In}(\mathrm{Zn}) \mathrm{P} / \mathrm{ZnS}$ core/shell nanoparticles grown at different reaction temperatures. Black and blue colored vertical lines at the bottom of the figure are added as the reference lines for InP and ZnS, respectively. The XRD patterns of the core nanoparticles are provided in the supplement.

alter the zinc blende crystal structure of $\operatorname{In}(\mathrm{Zn}) \mathrm{P} / \mathrm{ZnS} / \mathrm{DDT}$ core/ shell nanoparticles (Fig. 4), as verified by the identical XRD patterns. ${ }^{53}$ The (111), (220), and (311) planes shown in Fig. 4 were between the reference lines of InP (JCDS 32-452) and ZnS (JCPDS 77-2100). The shifts in the XRD peaks were observed depending on the different core reaction temperatures. It explains that the core reaction temperature affects the shell type of $\operatorname{In}(\mathrm{Zn}) \mathrm{P} / \mathrm{ZnS}$ nanoparticles as gradient or discrete shell layers. As a result, the length of the unit cell - lattice constant changes, and the strains of the nanoparticles are affected. ${ }^{54}$ Consequently, the shifts in the XRD pattern were observed.

Real-time, in situ PL spectra measured using an Ocean Optics fiber optics spectrometer were used to monitor the impact of the DDT coating on the fluorescence spectra. The bifurcated fiber-optic probe inserted in the batch reactor shown in Fig. 5a was used to excite nanoparticles at $405 \mathrm{~nm}$ and to collect fluorescence emissions with an integration time of 100 milliseconds. Fig. 5b shows the time-evolved fluorescence spectra of the nanoparticles with and without ZnS and DDT layers combined. The fluorescence intensity of the DDT-coated nanoparticles was further monitored over 35 days to demonstrate the stability of the nanoparticles (Fig. $5 \mathrm{c}$ ). The addition of inorganic and organic layers significantly improved the fluorescence emission intensity. The quantum yields of the nanoparticles were significantly increased by the addition of DDT in the last step of the reaction because it provides an organic shell layer to passivate surfaces and increase particle stability. ${ }^{55,56}$ It was also observed that the peak position and shape of the fluorescence spectrum during the shell layer formation did not change. The unchanged spectral features confirm that the fluorescence emission is due to the electron-hole pairs (excitons) confined in the nanoparticle core. ${ }^{57}$ The DDT coating increased fluorescence intensity by enabling surface passivation of the core/shell alloyed nanoparticles. ${ }^{58}$ Since DDT has a relatively shorter alkyl chain, the steric hindrance is less than the other mostly used organic ligands, and thereby higher surface coverage of DDT may be established to prevent photodegradation of the nanoparticles (Fig. S3, ESI $\dagger$ ). A slight blue shifting in the fluorescence spectrum after DDT addition was observed and attributed to ion exchange between smaller $\mathrm{S}^{2-}$ ions from DDT and larger $\mathrm{P}^{3-}$ ions in the nanoparticles. ${ }^{59}$

FTIR spectra of DDT remnant in solution and adsorbed onto InP/ZnS nanoparticle surfaces are shown in Fig. 6. 2985, 2930, and $2860 \mathrm{~cm}^{-1}$ bands are assigned to $\mathrm{C}-\mathrm{H}$ stretching, and the band at $1467 \mathrm{~cm}^{-1}$ is assigned to $\mathrm{CH}_{2}$ bending. ${ }^{60}$ The absence of the band at $2565 \mathrm{~cm}^{-1}$ indicating the stretching vibration mode of S-H (shown with a circle) proved that the DDT ligand was successfully attached to the nanoparticle surface. ${ }^{61,62}$ It is assumed that DDT molecules are bonded to In or $\mathrm{Zn}$ atoms on the nanoparticle surface through its sulfur atom. The sharpness of the $\mathrm{C}-\mathrm{H}$ stretching and $\mathrm{CH}_{2}$ bending modes suggests synchronized in-phase vibrations, inferring that DDT molecules are very well aligned on the
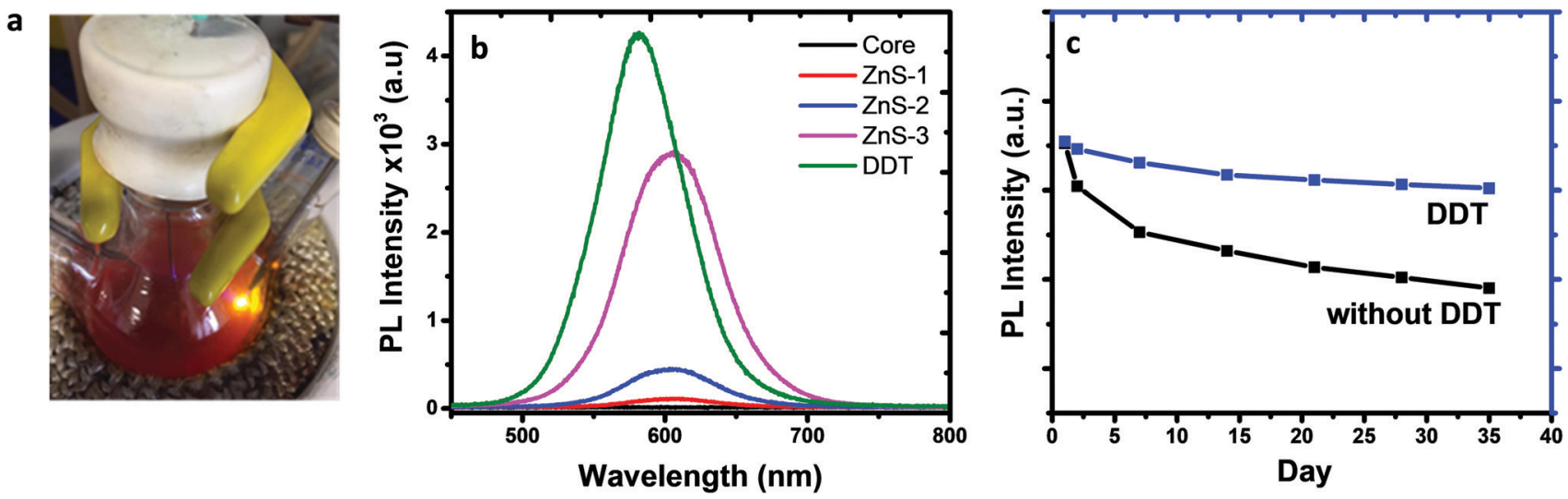

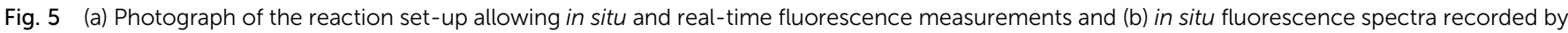

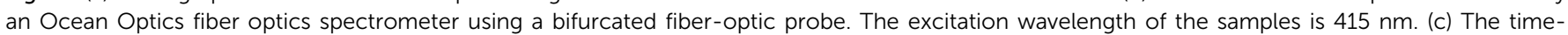
evolved fluorescence spectra and improved photostability of the nanoparticles with and without DDT coating. 


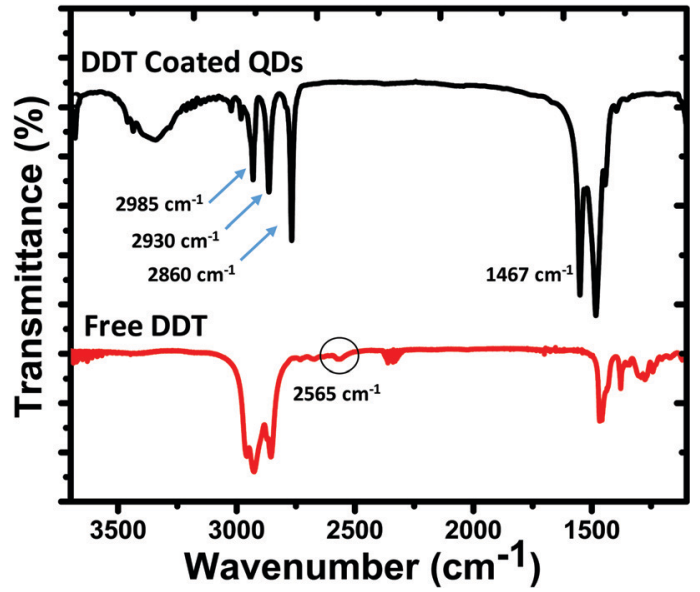

Fig. 6 FTIR spectra of remnant DDT and $\ln (\mathrm{Zn}) \mathrm{P} / \mathrm{ZnS}$ nanoparticles coated with DDT. The circled area at $2565 \mathrm{~cm}^{-1}$ is the $\mathrm{SH}$ vibrational mode, which is diminished after DDT bonding to the nanoparticle surfaces.

surfaces, reducing defects and dangling bonds, which increased quantum yields.

\subsection{Creating security patterns on various substrates using screen printing}

$\operatorname{In}(\mathrm{Zn}) \mathrm{P} / \mathrm{ZnS} / \mathrm{DDT}$ colloidal nanoparticles were used as pigments for ink formula to create security patterns, by exploiting their brighter fluorescence, increased bond strength by the alloy formation, and lower cost compared to the rare earth materials. Rare earth element-based inks have been used in security patterns for anticounterfeiting. ${ }^{1,2,63-65}$ Due to the high cost of the rare earth materials, security ink made with them may not be feasible for anticounterfeiting applications. The amount of fluorescent material is the key factor to formulate the ink. Generally, a high amount (5-25\%) of fluorescent material was required to formulate the ink. ${ }^{20,31,66,67}$ However, a significantly low amount $(0.1-0.2 \% \mathrm{v} / \mathrm{v})$ of highly fluorescent $\operatorname{In}(\mathrm{Zn}) \mathrm{P} / \mathrm{ZnS} / \mathrm{DDT}$ was used to formulate the security ink. When it is compared with the amount of fluorescent materials required in other studies, it is estimated that the printing cost would be approximately 250 times less due to the lower cost of In and lower amount of nanoparticles required to make the ink.

The fluorescent security ink formula was developed by uniformly dispersing the as-synthesized $\operatorname{In}(\mathrm{Zn}) \mathrm{P} / \mathrm{ZnS} / \mathrm{DDT}$ nanoparticles in a varnish/toluene mixture. Since the nanoparticle is highly luminous, a very low amount of nanoparticles, about $0.2 \% \mathrm{v} / \mathrm{v}$, can be utilized to formulate the low-cost ink. This ink was used to print a security pattern, a logo, on a nonluminous paper to demonstrate that the ink developed may be qualified for authenticating documents. All printed patterns were dried naturally under ambient conditions. The photographs illustrated screen printing security patterns on various substrates as shown in Fig. S4 (ESI $\dagger$ ). The patterns were barely observable on the paper substrate under daylight (Fig. 7) because the concentration of ink containing In(Zn)P/ZnS/DDT was very low. However, because of the high brightness (equal to $\mathrm{QY} \times \varepsilon$ ) of the nanoparticles, the security patterns with various fluorescence colors were easily observable under UV light (Fig. 7). The $\operatorname{In}(\mathrm{Zn}) \mathrm{P} / \mathrm{ZnS} / \mathrm{DDT}$ nanoparticles may emerge as a fluorescent pigment in the security ink, which is observable just under UV light. ${ }^{43}$ Fluorescent security patterns can be created with different printing techniques; ${ }^{68-72}$ however, the security level will be lowered if the patterns are visible under UV light illumination. Since security patterns could be easily reproduced by using fake fluorescent materials having similar spectral properties, an additional level of security feature should be added for enhanced authenticity.

A fiber spectrometer was used to collect emission spectra originating from the security patterns printed on the papers. The fluorescence spectra of the security patterns printed on a paper substrate using inks with and without $\operatorname{In}(\mathrm{Zn}) \mathrm{P} / \mathrm{ZnS} / \mathrm{DDT}$ nanoparticles were evaluated. While unprinted parts of the paper had almost no emission, the varnish without the nanoparticles printed on the paper substrates showed its specific broad emission at $494 \mathrm{~nm}$ (Fig. S5, ESI $\dagger$ ). The fluorescence emission spectra of the inks in the range from $535 \mathrm{~nm}$ to $638 \mathrm{~nm}$ (shown in Fig. 8) were collected by using a bifurcated fiber probe. The spectral features were easily distinguished in the printed patterns. The stereomicroscopic images of the security pattern under daylight and UV light illumination are

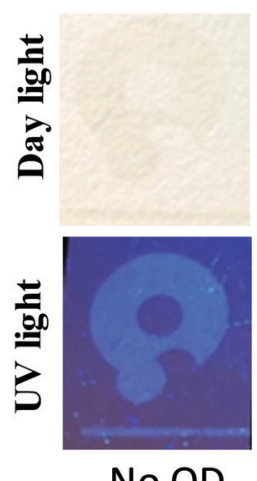

No QD

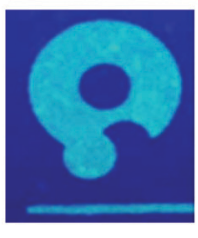

$535 \mathrm{~nm}$

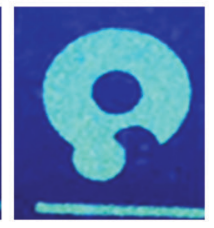

$550 \mathrm{~nm}$

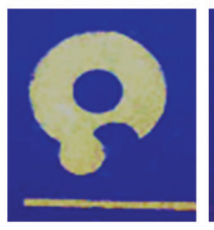

$573 \mathrm{~nm}$

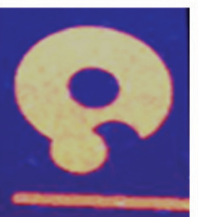

$602 \mathrm{~nm}$

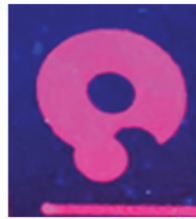

$638 \mathrm{~nm}$

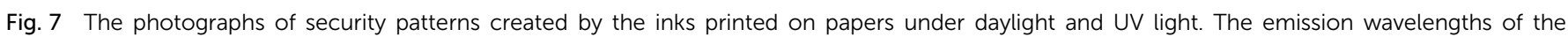
nanoparticles in the ink formula are given under the photographs. The concentration of the ink is $0.2 \% \mathrm{v} / \mathrm{v}$, allowing visible fluorescent patterns. 


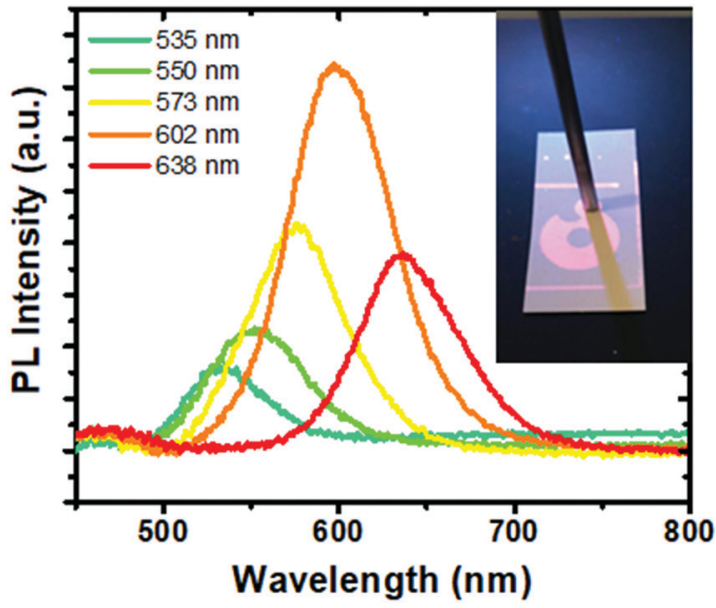

Fig. 8 The emission spectra of $\ln (Z n) P / Z n S / D D T$ nanoparticles collected from the fluorescent security patterns printed on the paper substrates. A bifurcated fiber-optic probe coupled to a spectrometer (a photograph in the inset shows the fiber-optic probe) was used to collect emission. The emission of the varnish (given in Fig. S5, ESI†) was subtracted from all the collected spectra. All samples were excited at $365 \mathrm{~nm}$.

also shown in Fig. S6 (ESI $\dagger$ ). The patterns were invisible under daylight in all the photographs. However, the patterns printed on the papers were easily observable under UV illumination. The homogeneity of the patterns indicates that nanoparticles are homogeneously distributed within the printed area.

To commercialize security inks, it is desired that security labels/codes should be produced by a low-cost ink and verified by a simple technique. Generally, the color information of fluorescent inks is encoded by tagging an anticounterfeiting pattern embedded onto substrates. To enhance the security level for anticounterfeiting, either advanced materials and/or techniques should be developed for verification of authenticity. Dual-excitation wavelength materials were used, so that the security pattern could be excited at two different wavelengths. ${ }^{9,20,73,74} \mathrm{QR}$ codes printed on products are also used as identification through reading by a device. ${ }^{3}$ However, since these codes can be completely duplicated, it lowers the security level. When an original QR code and a copied code are placed side by side and scanned by a smartphone, it will be very hard to identify which one is fake and which one is authentic. However, imitation can be made difficult to some extent when two different methods are applied. Herein, we developed a technology combining an optical device that reads novel security patterns/tags created with a specialty ink formula. Thus, unlike other studies, we can verify the security patterns/codes with a device that has optical sensitivity beyond visual inspection. To this end, a cost-effective fluorescent ink containing indium-based nanoparticles is formulated, enabling very low amounts of nanoparticles to be required in the ink. In addition, an optical device having an integrated light source and sensor is developed in-house. By virtue of the novel security tags containing low amounts of nanoparticles, the ink fluorescence may not be noticeable or hardly observable under UV light by visual inspection. The concentration of the nanoparticles in the ink was reduced to $0.1 \% \mathrm{v} / \mathrm{v}$. In Fig. $9 \mathrm{a}-\mathrm{f}$, the created security patterns/tags are presented under daylight and UV light. An additional varnish layer has been applied onto the security printing, and as a result, the security labels were not noticed even with the naked eye. In this way, security labels that are difficult to distinguish even under daylight have been created. In addition, fluorescent security patterns with distinct colors under UV illumination were not distinguishable due to the low concentration of nanoparticles in the ink. Herein, we used a fiber optics-based optical device (Quantag Sensor) that was employed to detect fluorescence emissions of the ink (Fig. 9g). The Quantag sensor includes one excitation fiber bringing a laser to the substrate to excite the ink, and collection fibers integrated with bandpass filters transmitting selected emissions to the sensor. ${ }^{75}$ The fluorescence intensities of the inks with different colors were detectable by the Quantag sensor, shown in Fig. 9h, but invisible by visual inspection (Fig. 9a-f). The Quantag sensor is highly sensitive, convenient, and specific to a predetermined wavelength compared to a fiber-optic spectrometer. These features add an extra security level for anticounterfeiting efforts. The fiber-optic spectrometer collects all the emissions including ink, varnish, and substrates, and cannot sort out the origin of the signals coming from different sources like the nanoparticles or varnish. However, since the Quantag sensor exploits emission filters, the predetermined emissions may be employed as a higher-level security code. The reduced ownership and operational costs and wavelength selectivity are also the advantages of the Quantag sensor compared to a commercial fiber-optic spectrometer, on top of being handy.

The photostability of the ink $(0.1 \% \mathrm{v} / \mathrm{v})$ embedded on the paper substrate was monitored for 21 days by the Quantag sensor. The fluorescence of the security patterns monitored proved that the intensities of the patterns were unchanged, as shown in Fig. 9h. The reduction in the intensity of the red-emitting ink $(638 \mathrm{~nm})$ may be explained by some sort of environmental effects on the nanoparticles emitting in this wavelength.

To understand the effect of substrate on the security pattern, the inks were applied to various substrates. The thickness of the patterns screen-printed on polymer and glass substrates was measured using an optical profilometer (Fig. S8, ESI $\dagger$ ). The thickness of the patterns was about $4.5 \mu \mathrm{m}$. These measurements confirmed that the security patterns form a thin film containing nanoparticles distributed homogeneously on the printed part of the substrates. The particle sizes have no effects on the film thickness. The confocal images are given in Fig. 10 showing some part of the logo patterns printed on the glass and polymer substrates. The logos were observable on the glass and polymer surfaces. These confocal images showed that the logo patterns were homogeneously printed on the substrates. In Fig. S9 (ESI $\dagger$ ), the logos printed with red fluorescent ink are imaged by using different objectives. For both polymer and glass substrates, the logos were imaged by using two different emission filters: a channel labeled as polymer channel collecting the emission/scattering coming from the varnish and substrate, and the channel labeled as QD channel collecting 

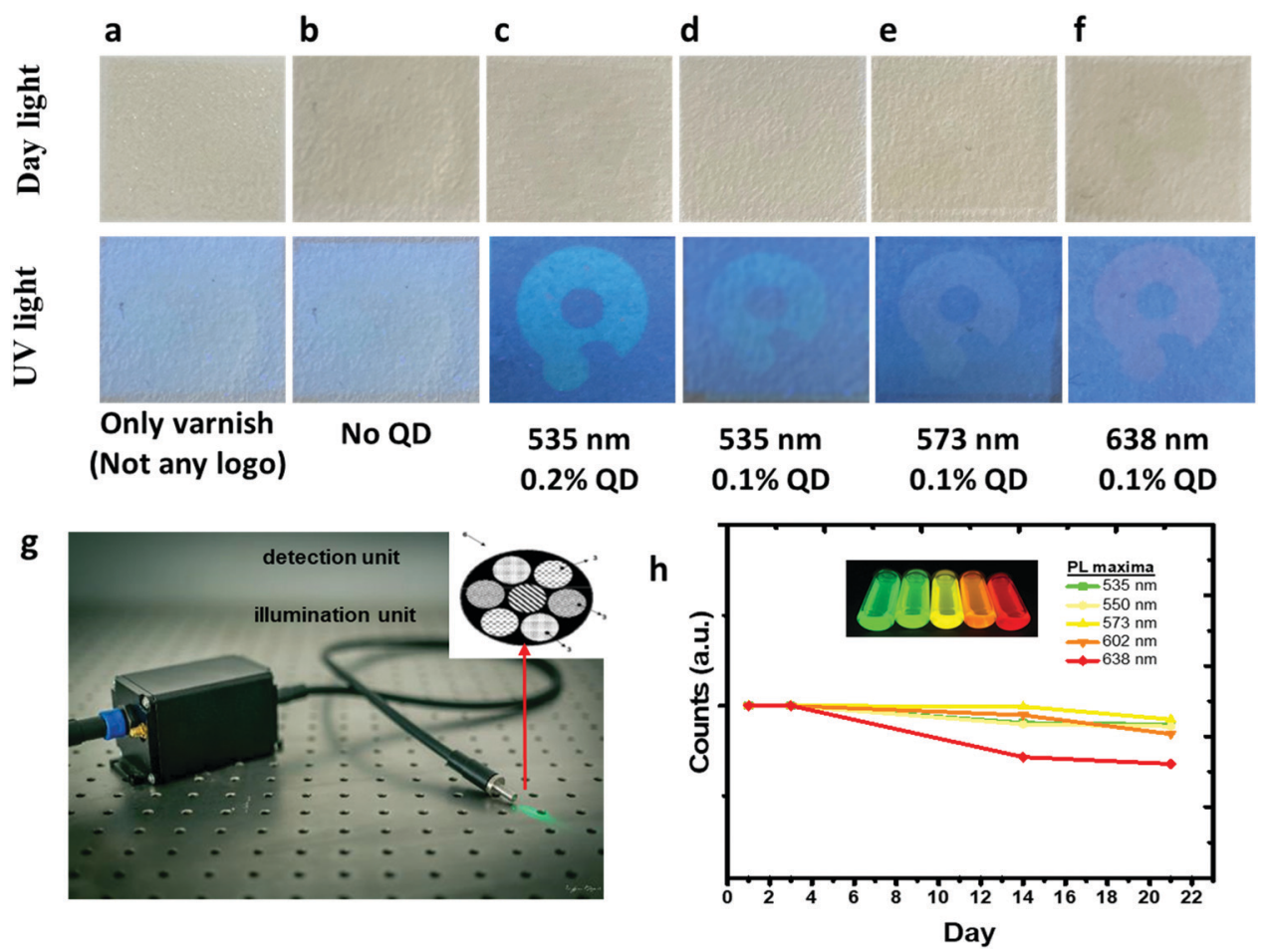

Fig. 9 (a-f) The security patterns created with fluorescent inks with and without nanoparticles printed on paper substrates. The nanoparticle concentrations are provided under the photographs. The security patterns were barely visible under daylight and slightly observable when illuminated by UV light by visual inspection. (g) The photograph shows the Quantag sensor having fiber optics and an integrated laser for excitation and collecting fibers as part of an optical readout unit. (h) The intensity of fluorescent inks $(0.1 \% \mathrm{v} / \mathrm{v})$ monitored by the Quantag sensor for 21 days, demonstrating the photostability of security patterns printed on the paper substrates. The inset in (h) shows emission colors of highly concentrated inks.

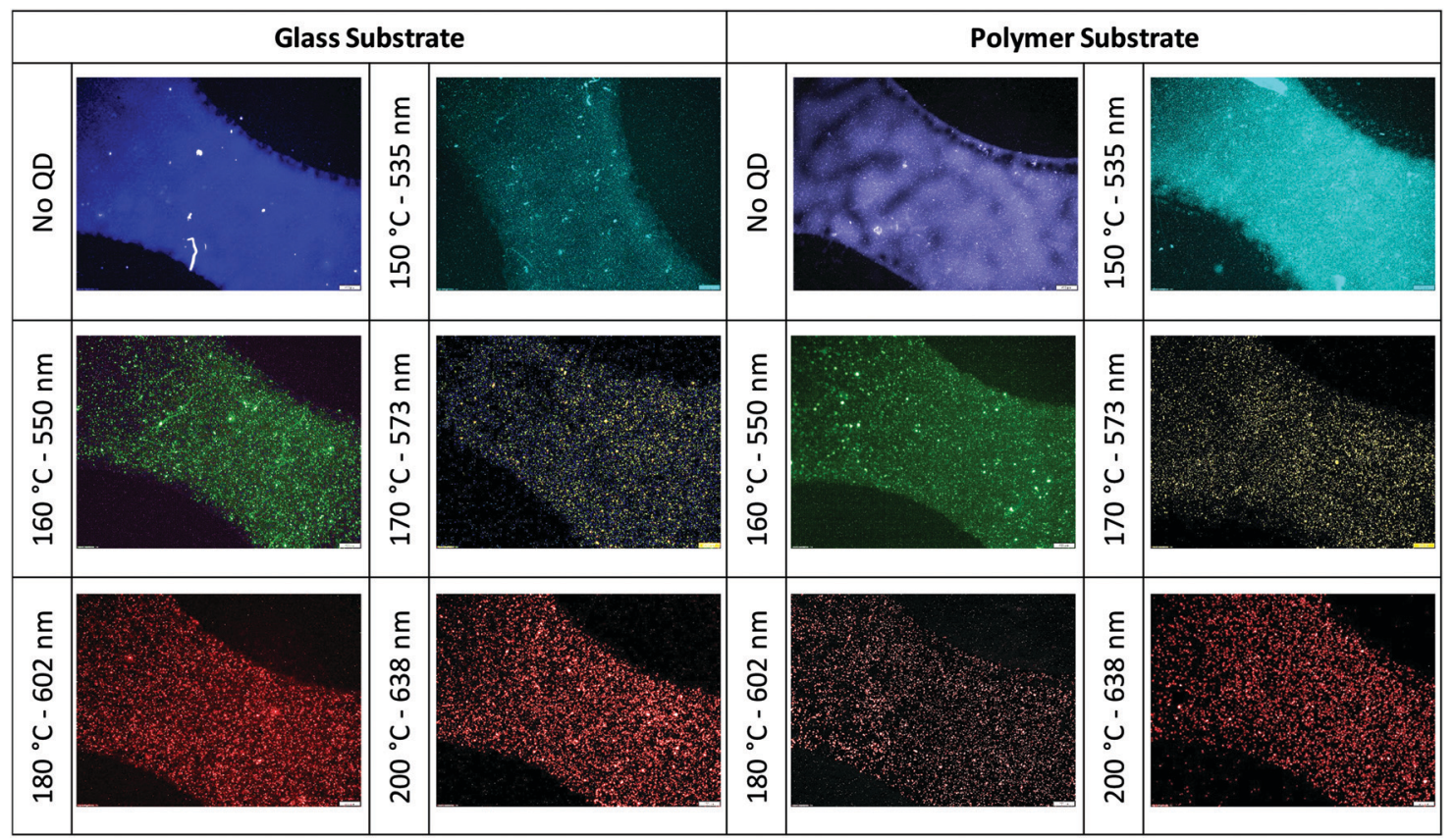

Fig. 10 Confocal images of a part of the printed logos, excited by a Hg lamb, on both glass and polymer substrates. The reaction temperature and the emission wavelength are provided on the left side of each photograph. The objective is $4 \times$ and the scale bar embedded in each image is $200 \mu m$. Homogeneous distribution of the nanoparticles dispersed in the varnish are clearly seen. 
the fluorescence emissions of the nanoparticles. These images verify that the nanoparticles are homogeneously dispersed in the ink and uniformly printed on the substrates.

\section{Conclusions}

Highly fluorescent $\operatorname{In}(\mathrm{Zn}) \mathrm{P} / \mathrm{ZnS} / \mathrm{DDT}$ colloidal nanoparticles are synthesized for anticounterfeiting applications. The DDT organic shell enhanced the particle stability and fluorescence brightness. The nanoparticles were homogeneously dispersed in a varnish to formulate colorless security inks. The formulated inks were utilized to create security patterns by applying screen printing techniques on various substrates including paper, polymer, and glass, demonstrating the capability of the ink for anticounterfeiting. The inks are transparent in the daylight, but strongly luminous in five different colors under UV light illumination. The security patterns created on the substrates are slightly visible in the daylight but almost colorless under UV light when the concentration of the nanoparticles was dropped to $0.1 \% \mathrm{v} / \mathrm{v}$. By using a lower amount of nanoparticles, the formula cost of the ink is substantially reduced. The invisible fluorescent inks as the security codes that cannot be perceived by visual inspection are clearly detectable by a handheld, low-cost optical device (Quantag sensor) that is developed in-house. The Quantag sensor is highly sensitive and selective to predetermined ink colors. The spectral information of the security patterns identified by the Quantag sensor is validated by a commercial fiber opticsbased spectrometer. However, the Quantag sensor has an advantage over the fiber-optical spectrometer, providing wavelength selectivity using narrow bandwidth emission filters. In summary, an anticounterfeiting technology is developed by combining invisible fluorescent inks with a hand-held, low-cost optical device to validate authenticity.

\section{Author contributions}

The manuscript was written by all the authors. All the authors have approved the final version of the manuscript. D. T.: carried out synthesis and characterization of nanoparticles, printed and analyzed security patterns screen-printed on substrates; investigation, methodology, and visualization, and wrote the original draft. S. S. Ü.: imaged the substrates by confocal microscopy and optical profilometer, and visualization and wrote the original draft. S. Ö.: conceptualization, writing - review \& editing of the manuscripts, supervision, and research administration.

\section{Funding sources}

Quantag Nanotechnologies supported this research.

\section{Conflicts of interest}

There are no conflicts to declare.

\section{Acknowledgements}

We acknowledge Quantag Nanotechnologies for their support. We also acknowledge IYTE Center for Materials Research for XRD measurements of the nanoparticles.

\section{References}

1 J. Y. Jung, J. Kim, Y. S. Shim, D. Hwang and C. S. Son, Materials, 2020, 13, 12.

2 T. O. Moon, J. Y. Jung and S. Cho, Korean J. Mater. Res., 2020, 30, 406-412.

3 M. L. You, M. Lin, S. R. Wang, X. M. Wang, G. Zhang, Y. Hong, Y. Q. Dong, G. R. Jin and F. Xu, Nanoscale, 2016, 8, 10096-10104. 4 J. S. Zhang and M. Q. Ge, J. Rare Earths, 2012, 30, 952-957. 5 L. Chen, Y. Zhang, A. Q. Luo, F. Y. Liu, Y. Jiang, Q. Z. Hu, S. F. Chen and R. S. Liu, Phys. Status Solidi RRL, 2012, 6, 321-323.

6 H. Huang, J. K. Chen, Y. T. Liu, J. D. Lin, S. X. Wang, F. Huang and D. Q. Chen, Small, 2020, 16, 12.

7 S. X. Wang, J. D. Lin, Y. W. He, J. K. Chen, C. B. Yang, F. Huang and D. Q. Chen, Chem. Eng. J., 2020, 394, 10.

8 J. D. Lin, C. B. Yang, P. Huang, S. X. Wang, M. L. Liu, N. Z. Jiang and D. Q. Chen, Chem. Eng. J., 2020, 395, 8.

9 M. X. Li, W. J. Yao, J. Liu, Q. Y. Tian, L. Liu, J. Ding, Q. W. Xue, Q. $\mathrm{Lu}$ and W. Wu, J. Mater. Chem. C, 2017, 5, 6512-6520.

10 K. Cheng, R. Qi, S. Lan, H. Y. Wang, X. F. Zheng, C. Liu, D. D. Jia, L. Cao and D. J. Wang, Dyes Pigm., 2020, 174, 10.

11 Z. Fatahi, N. Esfandiari and Z. Ranjbar, J. Anal. Test., 2020, 4, 307-315.

12 L. Y. Jiao, M. N. Zhang and H. B. Li, Materials, 2020, 13, 13. 13 L. Ju, W. B. Gao, J. Y. Zhang, T. Y. Qin, Z. Du, L. Sheng and S. X. A. Zhang, J. Mater. Chem. C, 2020, 8, 2806-2811.

14 Y. Liu, F. Han, F. S. Li, Y. Zhao, M. S. Chen, Z. W. Xu, X. Zheng, H. L. Hu, J. M. Yao, T. L. Guo, W. Z. Lin, Y. H. Zheng, B. G. You, P. Liu, Y. Li and L. Qian, Nat. Commun., 2019, 10, 9.

15 R. Platel, L. Vaure, E. Palleau, S. Raffy, F. Guerin, D. Lagarde, R. Cours, C. Marcelot, B. Warot-Fonrose, C. Nayral, F. Delpech and L. Ressier, J. Colloid Interface Sci., 2021, 582, 1243-1250.

16 T. P. Nguyen, T. P. Nguyen, Q. V. Lam and T. B. Vu, Solid State Sci., 2020, 101, 9.

17 S. Khan, L. Lorenzelli and R. S. Dahiya, IEEE Sens. J., 2015, 15, 3164-3185.

18 S. M. F. Cruz, L. A. Rocha and J. C. Viana, Flexible Electronics, 2018, ch. 3, DOI: 10.5772/intechopen.76161.

19 M. Saraf, P. Kumar, G. Kedawat, J. Dwivedi, S. A. Vithayathil, N. Jaiswal, B. A. Kaipparettu and B. K. Gupta, Inorg. Chem., 2015, 54, 2616-2625.

20 C. Zhang, X. Li, M. L. Liu, T. T. Li, T. X. Yu, Y. Li, J. Zhang, A. M. Asiri, K. A. Alamry and K. Zhang, J. Alloys Compd., 2020, 836, 7.

21 X. Chen, W. Yao, Q. Wang and W. Wu, Adv. Opt. Mater., 2019, 8, 1901209.

22 W. Yao, Q. Tian and W. Wu, Adv. Opt. Mater., 2019, 7, 1801171.

23 L. Z. Chen, B. A. Hu, J. Y. Zhang, J. M. Zhang, S. T. Huang, P. Ren, Y. Zou, F. Y. Ding, X. H. Liu and H. B. Li, RSC Adv., 2019, 9, 476-481. 
24 M. Zhou, S. Chang and C. Grover, Opt. Express, 2004, 12, 2925-2931.

25 T. Jamieson, R. Bakhshi, D. Petrova, R. Pocock, M. Imani and A. M. Seifalian, Biomaterials, 2007, 28, 4717-4732.

26 M. Henriksen, B. Miller, J. Newmark, Y. Al-Kofahi and E. Holden, Methods Cell Biol., 2011, 102, 161-205.

27 E. M. Janke, N. E. Williams, C. She, D. Zherebetskyy, M. H. Hudson, L. Wang, D. J. Gosztola, R. D. Schaller, B. Lee, C. Sun, G. S. Engel and D. V. Talapin, J. Am. Chem. Soc., 2018, 140, 15791-15803.

28 B. K. Gupta, D. Haranath, S. Saini, V. N. Singh and V. Shanker, Nanotechnology, 2010, 21, 055607.

29 X. J. Fu, G. Q. Li, S. Y. Cai, H. Yang, K. Lin, M. He, J. W. Wen, H. B. Li, Y. B. Xiong, D. Z. Chen and X. H. Liu, Carbohydr. Polym., 2021, 251, 9.

30 F. F. Du, Z. H. Guo, Z. Cheng, M. Kremer, S. M. Shuang, Y. Liu and C. Dong, Nanoscale, 2020, 12, 20482-20490.

31 Z. B. Wang, P. X. Pei, D. J. Bai, S. S. Zhao, X. Y. Ma and W. S. Liu, Inorg. Chem. Front., 2020, 7, 2506-2514.

32 S. X. Wang, J. D. Lin, X. Y. Li, J. K. Chen, C. B. Yang, P. Huang, Y. Cheng and D. Q. Chen, J. Mater. Chem. C, 2020, 8, 16151-16159.

33 W. Zheng, B. Y. Sun, Y. M. Li, R. Wang and Y. L. Xu, Mater. Chem. Front., 2019, 3, 2403-2413.

34 J. Y. Jung, B. K. Song and Y. K. Kim, J. Alloys Compd., 2019, 791, 81-86.

35 C. Ippen, B. Schneider, C. Pries, S. Kröpke, T. Greco and A. Holländer, Nanotechnology, 2015, 26, 085604.

36 K. Kim, S. Jeong, J. Y. Woo and C. S. Han, Nanotechnology, 2012, 23, 065602.

37 M. D. Tessier, D. Dupont, K. De Nolf, J. De Roo and Z. Hens, Chem. Mater., 2015, 27, 4893-4898.

38 P. Mushonga, M. O. Onani, A. M. Madiehe and M. Meyer, J. Nanomater., 2012, 2012, 1-11.

39 E. E. L. Langof, E. Lifshitz, O. I. Micic and A. J. Nozik, J. Phys. Chem. B, 2002, 106, 1606-1612.

40 S. B. Brichkin, Colloid J., 2015, 77, 393-403.

41 N. Mordvinova, A. Vinokurov, T. Kuznetsova, O. I. Lebedev and S. Dorofeev, Dalton Trans., 2017, 46, 1297-1303.

42 U. T. D. Thuy, P. T. Thuy, N. Q. Liem, L. Li and P. Reiss, Appl. Phys. Lett., 2010, 96, 073102.

43 R. P. Brown, M. J. Gallagher, D. H. Fairbrother and Z. Rosenzweig, Langmuir, 2018, 34, 13924-13934.

44 S. Tamang, C. Lincheneau, Y. Hermans, S. Jeong and P. Reiss, Chem. Mater., 2016, 28, 2491-2506.

45 W. Shen, H. Tang, X. Yang, Z. Cao, T. Cheng, X. Wang, Z. Tan, J. You and Z. Deng, J. Mater. Chem. C, 2017, 5, 8243-8249.

46 S. Haubold, M. Haase, A. Kornowski and H. Weller, ChemPhysChem, 2001, 2, 331-334.

47 X. Fang, T. Zhai, U. K. Gautam, L. Li, L. Wu, Y. Bando and D. Golberg, Prog. Mater. Sci., 2011, 56, 175-287.

48 J. Zhang and H. Gu, Dalton Trans., 2020, 49, 6119-6126.

49 J.-H. Jo, D.-Y. Jo, S.-H. Lee, S.-Y. Yoon, H.-B. Lim, B.-J. Lee, Y. R. Do and H. Yang, ACS Appl. Nano Mater., 2020, 3, 1972-1980.

50 J. Lim, W. K. Bae, D. Lee, M. K. Nam, J. Jung, C. Lee, K. Char and S. Lee, Chem. Mater., 2011, 23, 4459-4463.
51 F. Pietra, L. De Trizio, A. W. Hoekstra, N. Renaud, M. Prato, F. C. Grozema, P. J. Baesjou, R. Koole, L. Manna and A. J. Houtepen, ACS Nano, 2016, 10, 4754-4762.

52 X. Zhang, H. Lee, J. H. Kwon, E. J. Kim and J. Park, Materials, 2017, 10, 880.

53 F. Angel-Huerta, M. P. González-Araoz, J. S. Arias-Cerón, J. F. Sánchez-Ramírez, J. Díaz-Reyes, J. L. Herrera-Pérez and J. G. Mendoza-Álvarez, J. Mater. Sci.: Mater. Electron., 2018, 29, 15649-15657.

54 S. H. Lee, Y. Kim, H. Jang, J. H. Min, J. Oh, E. Jang and D. Kim, Nanoscale, 2019, 11, 23251-23258.

55 L. Li and P. Reiss, J. Am. Chem. Soc., 2008, 130, 11588-11589. 56 C. Xia, J. D. Meeldijk, H. C. Gerritsen and C. de Mello Donega, Chem. Mater., 2017, 29, 4940-4951.

57 Y. A. Alemu, Synthesis, Surface Treatment, and Characterization of Copper Indium Sulfide Quantum Dots, Master of Science, Oregon State University, 2016.

58 M. T. Clarke, F. N. Viscomi, T. W. Chamberlain, N. Hondow, A. M. Adawi, J. Sturge, S. C. Erwin, J.-S. G. Bouillard, S. Tamang and G. J. Stasiuk, Commun. Chem., 2019, 2, 36.

59 T. Kim, S. W. Kim, M. Kang and S.-W. Kim, J. Phys. Chem. Lett., 2012, 3, 214-218.

60 T. Watanabe, C. Wada, Y. Iso, T. Isobe and H. Sasaki, ECS J. Solid State Sci. Technol., 2017, 6, R75-R80.

61 J. Chang and E. R. Waclawik, CrystEngComm, 2013, 15, 5612-5619.

62 S. Feizi, H. Zare and M. Hoseinpour, Appl. Phys. A: Mater. Sci. Process., 2018, 124, 1-7.

63 W. Yan, G. X. Bai, R. G. Ye, X. L. Yang, H. Q. Xie and S. Q. Xu, Opt. Commun., 2020, 475, 7.

64 Y. Hua, S. K. Hussain and J. S. Yu, J. Alloys Compd., 2020, 826, 14.

65 J. Xu, B. B. Zhang, L. Jia, Y. P. Fan, R. J. Chen, T. H. Zhu and B. Z. Liu, ACS Appl. Mater. Interfaces, 2019, 11, 35294-35304.

66 W. J. Yao, Q. Y. Tian, J. Liu, Q. W. Xue, M. X. Li, L. Liu, Q. Lu and W. Wu, Nanoscale, 2017, 9, 15982-15989.

67 K. S. Nair, P. Abhilash and K. P. Surendran, ACS Omega, 2019, 4, 2577-2583.

68 B. Chen, H. P. Xie, S. Wang, Z. Y. Guo, Y. F. Hu and H. Z. Xie, Luminescence, 2019, 34, 437-443.

69 P. Yang, Z. Q. Zhu, T. Zhang, M. Z. Chen, Y. Z. Cao, W. Zhang, X. Wang, X. Y. Zhou and W. M. Chen, Carbon, 2019, 146, 636-649.

70 S. J. Park, J. Y. Park and H. K. Yang, Sens. Actuators, B, 2018, 262, 542-554.

71 J. Andres, R. D. Hersch, J. E. Moser and A. S. Chauvin, Adv. Funct. Mater., 2014, 24, 5029-5036.

72 Y. L. Liu, K. L. Ai and L. H. Lu, Nanoscale, 2011, 3, 4804-4810.

73 P. Kumar, J. Dwivedi and B. K. Gupta, J. Mater. Chem. C, 2014, 2, 10468-10475.

74 N. M. Sangeetha, P. Moutet, D. Lagarde, G. Sallen, B. Urbaszek, X. Marie, G. Viau and L. Ressier, Nanoscale, 2013, 5, 9587-9592.

75 H. Urey, O. V. Akgun, E. Heves, F. Civitci and B. Can, A Fluorescent substance detection system, Turkey Pat., WO 2016/ 010494, 2016. 